\title{
Prevalence and age of onset for drug use in seven international sites: results from the international consortium of psychiatric epidemiology
}

\author{
William A. Vega ${ }^{a,}$, Sergio Aguilar-Gaxiola ${ }^{b}$, Laura Andrade ${ }^{c}$, Rob Bijl ${ }^{\text {d }}$, Guilherme Borges \\ ${ }^{\mathrm{e}}$, Jorge J. Caraveo-Anduaga ${ }^{\mathrm{e}}$, David J. DeWit ${ }^{\mathrm{f}}$, Steven G. Heeringa ${ }^{\mathrm{g}}$, Ronald C. Kessler ${ }^{\mathrm{h}}$, \\ Bo Kolody ${ }^{\text {i }}$, Kathleen R. Merikangas ${ }^{j}$, Beth E. Molnar ${ }^{\text {h}}$, Ellen E. Walters ${ }^{\text {h }}$, Lynn A. Warner \\ , Hans-Ulrich Wittchen ${ }^{1}$
}

a Institute for Quality, Research, and Training, Robert Wood Johnson Medical School-UMDNJ, 335

George Street, 3rd Floor, Liberty Plaza, New Brunswick, NJ 08901, USA

b California State University at Fresno, Fresno, CA 93740, USA

c University de Sao Paulo, Sao Paulo 05403-010, Brazil

d Netherlands Institute of Mental Health and Addiction, Utrecht, The Netherlands

e Mexican Institute of Psychiatry, Mexico City, Mexico

f Addiction Research Foundation, Centre for Addiction and Mental Health, London, Ont., Canada

g University of Michigan, Ann Arbor, MI 48106, USA

h Harvard Medical School, Boston, MA, USA

i San Diego State University, San Diego, CA, USA

j Yale University, New Haven, CT 06510, USA

k Rutgers University, New Brunswick, NJ 08901, USA

1 Max Planck Institute of Psychiatry, D-80804 Munich, Germany

\begin{abstract}
This study compares lifetime prevalence and age of first use (onset) for alcohol, cannabis, and other drugs in six international sites. Data from seven epidemiologic field surveys that used compatible instruments and study designs were compiled for cross-site analyses by the International Consortium of Psychiatric Epidemiology (ICPE). The world health organization's composite international diagnostic instrument (WHO-CIDI) and additional items were used to ascertain drug use in each site. Lifetime use rates were estimated for alcohol, cannabis, and other illicit drugs. Survival analyses were used to estimate age of onset. Study settings and main results: use of alcohol twelve or more times ranged in descending order from the Netherlands (86.3\%), United States $(71.7 \%)$, Ontario, Canada (71.6\%); São Paulo, Brazil (66.1\%), Munich, Germany (64.9\%), Fresno, California (USA) (51.9\%), to Mexico City (43.2\%). Use of cannabis five or more times in a lifetime ranged from 28.8 in the United States to $1.7 \%$ in Mexico City, and other drugs ranged from United States (19.4\%) to Mexico City $(1.7 \%)$. Age of first use was similar across study sites. This study demonstrates the fundamental uniformity of onset patterns by age as contrasted with wide variations in lifetime prevalences across sites. Study findings suggest that drug use patterns may change among emigrating populations from low consumption nations as a consequence of international resettlement in nations with higher rates. Methodological limitations of the study along with recommendations for future international comparative research are discussed.
\end{abstract}

Keywords: Alcohol; Drugs; International; Prevalence; Onset; Epidemiology 


\section{Introduction}

Substance abuse produces an enormous burden on many societies. For example, in the United States the impact of substance abuse on health care, criminal justice system, and related economic burdens, was estimated at $\$ 414$ billion in 2001 (Hegan et al., 2001). It is important to understand how drug use patterns are changing throughout the world. Cross-national and regional studies provide a benchmark for evaluating trends and cyclical shifts in drug use. This information is useful for assessing the feasibility of public policies for control and prevention of substance abuse, and for estimating economic costs of drug and alcohol use in different societies. These studies can be used to address basic substance abuse research issues such as the economic, social, and cultural determinants of prevalence, intensity, progression, and co-morbidity (Kessler et al., 1999; Merikangas et al., 1998). This article presents information about lifetime prevalence rates and age of onset for alcohol, cannabis, and other drug use reported from several nations and regional sites in North America and Europe. Results from these studies have been aggregated through the auspices of the international consortium of psychiatric epidemiology (ICPE).

In the absence of readily available national survey data, the United Nations has often relied on reports of treatment seeking, convenience samples, and narcotics trafficking to estimate the intensity of international drug use (Adrian, 1996). However, these approaches are misleading for making population estimates of lifetime drug use. A persistent limitation of using surveys conducted in North America and Europe for making epidemiologic comparisons is the noncomparability of designs and protocols. This problem has impeded the compilation of databases from various countries suitable for cross-site analyses of rates and patterns of use (Jutkowitz and Eu, 1994; Hughes et al., 1983; Smart and Murray, 1985). Comparability is the standard of a truly international epidemiology of drug use, and until now this has only been possible in alcohol studies.

Most national surveys reported in the public health and substance abuse literature are about adolescent drug use. These studies have estimated rates of drug use using school-based samples (Vega et al., 1998; Adlaf et al., 1997; Johnston et al., 1997; Smart et al., 1988; DeZwart et al., 1997; Caravalho et al., 1995; Medina- Mora et al., 1993; Scholz and Kaltenbach, 1995; Uchtenhagen, 1984; Driessen et al., 1989; Korf, 1988). Important exceptions are the surveillance data about adults collected regularly by survey in the United States (National Institute on Drug Abuse, 1998) and Canada (Xie et al., 1998). Also, two national surveys conducted in the United States within the past decade provided extensive information about drug use prevalence and correlates, the National Comorbidity Survey (NCS; Kessler, 1995) and the National Longitudinal Alcohol Epidemiologic Survey (Grant, 1996, 1997). Other examples of multiple national and metropolitan adult drug use surveys are found in Mexico (Galvan-Reyes et al., 1997; Tapia-Conyer et al., 1996) and the City of Amsterdam in the Netherlands, which also is the site for periodic adult surveys (Sandwijk et al., 1991). Collectively, these surveys have estimated adult substance use, primarily for alcohol.

National studies that have compared alcohol use and rates for other drugs routinely report that alcohol is the most widely used substance (Perkonigg et al., 1998; Holly and Wittchen, 1998; Senay, 1991). Cross-national rates for lifetime alcohol use are similar in the United States, Canada, and in Europe. Variations in alcohol use rates in these societies are primarily a function of gender and cultural norms and legal controls governing use, including differences in the age of legal alcohol use. Consistently, women have lower lifetime rates than men. The sex differential is greatest in Latin American countries, such as Mexico, where cultural 
practices both constrain and sanction use of alcohol by women (Caetano and Carlini-Cotrim, 1993; Caraveo-Anduaga et al., 1999). Much greater variation is found in epidemiologic estimates of cannabis use. The United States, Canada, Australia, and New Zealand report higher rates, in the range of $30 \quad / 50 \%$ lifetime use (National Drug Strategy, 1996; Black and Casswell, 1993). European and Latin American nations are in a range from 5 to $15 \%$ (MacCoun and Reuter, 1997). Total international lifetime use of cannabis is estimated at 141 million users (United Nations International Drug Control Programme, 1997). Regrettably, adequate data for estimating cocaine and other drug use are less available or reliable, but what has been reported mirrors cross-national variations in rates of cannabis use. The United States and Canada have far higher prevalence levels than other nations in recent decades since WWII (Erickson et al., 1987).

\section{Methods}

\subsection{Samples}

Seven surveys carried out in six countries are included in these analyses. Descriptive information about the seven surveys and locations is presented in Table 1 with appropriate references. These references provide details on the study designs. The surveys were carried out in North America, Latin America, and Europe, with a total sample size of 27255 . All surveys were based on general population probability samples rather than on patient samples or quota samples of the general population. All interviews were carried out face-to-face rather than on the telephone or through mail questionnaires. The age ranges for the respective samples are shown in Table 1, and the age range for the analyses presented below was limited to 14-54 year olds across sites. Response rates in the separate surveys were between 60.4 and $90.0 \%$. This study compares regional and national samples. These samples include one regional study from Central (Fresno) California to contrast patterns of drug use prevalence and onset among Mexican Americans with samples from Mexico City and the USA. This offers an opportunity to examine what happens to rates of drug use consumption when individuals migrate from one nation to another.

\subsection{Substance use variables}

The lifetime estimates presented in this paper include drugs not available through medical sources, including physicians, and substances that are legitimate pharmaceutical products but were consumed without prescription or at amounts other than those prescribed by a medical professional. The drug groups include, (1) alcohol; (2) cannabis including marijuana and hashish; (3) opioids including heroin, morphine and other analgesics such as codeine; (4) stimulants other than cocaine such as methamphetamine; (5) anxiolytics such as sedatives and tranquilizers; (6) psychedelics such as LSD, peyote; and mescaline; (7) cocaine; and (8) inhalants such as gasoline or spray paint. Lifetime estimates for the use of these substances is based on reported use of alcohol at least 12 times and other substances on at least five occasions. Comparisons of prevalence rates for Germany were limited in scope because the sample was restricted to the age range 14-24.

\subsection{Data analysis}

Analyses presented in the tables and figures of this paper incorporate the design features of the probability samples for each survey data set including stratification and clustering of sample individuals and weighting of responses. All estimates are weighted by case-specific analysis weights designed to compensate for varying selection probabilities, differential non- 
response rates and available post-stratification adjustments (Heeringa et al., 1997). Although other procedures are available, compensation was used for differential selection probabilities and response rates in making estimations. Post-stratification weighting of sample estimates was used to reduce potential bias due to sample non-coverage of the target populations (Little, 1991). Standard errors of prevalence estimates reported in the tables of this paper were computed using special software for Jackknife repeated replications (JRR) variance estimation and reflect the effects of the surveys' complex sample designs and poststratification adjustments (Wolter, 1965).

Prevalence estimates of lifetime substance abuse reported from surveys other than the ICPE surveys were not re-estimated from original data but are presented as given in other published sources (Table 1). ICPE survey estimates of lifetime prevalence of substance abuse for total populations (Table 2) and genders (Table 3 ) are weighted estimates computed using the combined ratio estimator of population proportions, $r=\Sigma i$ WiYi / $\Sigma i \mathrm{Wi}$, where $Y i=1$ if case $i$ meets lifetime criteria, 0 otherwise, and $\mathrm{Wi}$ is the analysis weight for the $\mathrm{i}$-th sample case (Kish, 1965).

Age of onset analyses are reported as weighted estimates of age-specific hazard rates for first use of a substance (Kalbfleisch and Prentice, 1980). The analyses are based on survey data from four of the seven sites: NCS, Fresno, Mexico City and Ontario. All estimates of agespecific hazards rates were computed using the SAS® PROC LIFETEST procedure. Hazard rate estimates were computed by the life table method. The estimated agespecific hazard rates are evaluated at the midpoint of each yearly age interval and were not adjusted in this analysis for other covariates such as gender or birth-year cohort. Weighted survey estimates of the agespecific hazard rates were achieved by substituting weighted frequencies in the estimation of age-specific 'failurerates,' where a 'failure' is interpreted as the experience of first use of a substance. Thus, the hazard rate for first use of a substance at age $t$ is estimated as:

$\hat{\mathrm{h}}(\mathrm{t})=\hat{\mathrm{q}}(\mathrm{t}) /(1-\hat{\mathrm{q}}(\mathrm{t}) / 2)$

where, ${ }^{\mathrm{q}} \mathrm{q}(\mathrm{t})=\mathrm{d}(\mathrm{t}) / \mathrm{n}(\mathrm{t})$ is the 'failure rate' at time $\mathrm{t}$; $\mathrm{d}(\mathrm{t})$ is the weighted count of first uses of a substance at time $t ; n(t)$ is the weighted count of persons 'at risk' at time $t$.

\section{Results}

Estimates (with standard errors) of the lifetime prevalence of substance use for individual drugs are presented in Table 2. Although alcohol and cannabis are the most widely consumed substances across all sites, prevalence rates of other drugs are extremely varied. For example, inhalant use is highest in the United States and São Paulo, Brazil, compared with all other national sites. Cannabis and cocaine use is minimal in Mexico City. Alcohol use is significantly higher in the Netherlands $(86.3 \%)$ than in any other site. Overall drug use rates are highest in the United States, Ontario and São Paulo, Brazil, ranging from 32.5 to $24.7 \%$. In sites other than Fresno, California, total lifetime prevalence ranges from 16.6\% in 14-24year olds in Munich, Germany, to a low of $2.9 \%$ in Mexico City.

The lifetime rates in Fresno, Central California, are of special interest in these comparisons because this sample consists of Mexican-origin respondents, divided between immigrants $(60.3 \%)$ and those born in the US (39.7\%). They represent a population whose cultural antecedents are in Mexico, the country with the lowest rates of drug use, yet they are residing in the United States, a country with very high rates. The Fresno rates are lower than the national US rates derived from the NCS. Nevertheless, the Fresno rate $(24.6 \%)$ is equivalent 
to Ontario (25.9\%), and São Paulo (24.7\%). These comparisons illustrate the increase in illicit drug use rates of re-socialization into American society primarily by first and secondgeneration immigrants originating from a nation with a low prevalence of drug use.

Table 3 presents lifetime substance use rates by gender, with standard errors. Cannabis is the second most likely drug to be used by both genders. Men have higher prevalence levels for alcohol, cannabis, and other drugs in all cross-national sites, but there are very wide variations across sites in rates for both genders. For example, lifetime use of cannabis among males ranges from 33.1 (NCS, USA) to 3.0\% (Mexico City), and for women from 24.4 (NCS, USA) to $0.6 \%$ (Mexico City). Rates in Munich, Germany, and the Netherlands for cannabis are intermediate for both genders.

In the Fresno sample, all gender comparisons are statistically significant. The rates for any drug use excluding cannabis among Fresno males is about the same as the NCS, USA rate for males, but the female rates are much higher in the NCS, USA, 17.1 and $10.8 \%$, respectively. In comparison, gender differences in Mexico are not significant in five instances because the overall prevalence levels are negligible, except for alcohol. Other instances of minimal gender differences tend to occur in countries where overall use of particular drugs is low, such as inhalant use in Ontario, Canada, the Netherlands, and Munich, Germany, or opioid use in the Netherlands and São Paulo, Brazil, and psychedelics in São Paulo, Brazil, and in Munich, Germany.

Women have major variations in rates of lifetime alcohol use across sites. Men and women of the Netherlands have the highest rates reported in this study, and women's rates in that nation are higher than those reported by men in three sites, Mexico City, Munich, Germany, and Fresno, California. The female rate in the Netherlands for alcohol is four times higher than reported by women in Mexico City.

Figs. 1-3 display age of onset (first use) information from the NCS, USA, Fresno, California, Mexico City, and Ontario, Canada surveys. Life table models were used to estimate agespecific hazard rates for first use of alcohol, cannabis, and other drug use, in a lifetime. These hazard rates can be interpreted as the rates that persons of a specific age (who have not yet experienced first use) experience first use. Fig. 1 illustrates that alcohol use onset increases at age 11 , and the curve accelerates in mid-adolescence to a peak age of 18 . This is followed by a rapid decrease in new onsets during early adult hood (the early twenties) and a gradual tapering off thereafter. These patterns are fairly uniform.

Fig. 2 presents cannabis use onset information. Cannabis has a short but intense onset period with rapid acceleration of first use between mid and late adolescence, then a rapid decrease after age 18 in the NCS, USA, 17 in Fresno, and 16 in Ontario, Canada. Although the rates are much lower, the age of onset pattern in Mexico City is similar to other samples in this study.

Fig. 3 shows that drugs other than alcohol and cannabis have a longer onset curve, with lower onset rates during adolescence, but new onsets extending into middle adulthood. Peak age of first use in all sites occurs at age 18 .

\section{Discussion}

We find great variation in rates of drug and alcohol use across the international samples reported in this study. Historically, higher population prevalence for illicit drug use has been reported in the United States than in other Western nations. Despite the ebb and flow of drug 
epidemics, rates remain very high. Ontario, Canada, appears to lag the US rates but may be reaching parity for some drugs. Mexico City, by comparison, has very low rates. Today, the Netherlands stands out prominently as having the highest alcohol rates among international sites in this study. These facts require scrutiny by public health policy and substance abuse experts in order to interpret their implications for future trends in all forms of drug use within and among nations. Given the findings we report, interpretations must be cautious and tentative. For example, very high rates of alcohol use in the Netherlands do not appear to have a strong influence on drug use rates, yet in the US a strong case could be made for this linkage. This finding alone opens the door to complex interpretations of public policy implications at both the individual (e.g. biogenetic vs. normative structures) and society levels (e.g. marketing vs. social control).

Several decades of information about per capita alcohol use indicates substantial increases in consumption after WWII (Smart, 1989; Soyka, 1998). Consumption may have peaked in the United States, even as it increases in Latin America (US Department of Health and Human Services, 1997; Williams et al., 1994). Higher consumption levels may partially reflect a lower mean age of onset for drinking. US rates of illicit drug use appear to have increased from WWII until the 1980s, then reduced significantly thereafter (Grant, 1997; Anthony and Helzer, 1991; Abelson and Miller, 1985; Burke et al., 1991; Johnston et al., 1997; SAMHSA, 1996). However, surveys conducted in the late 1980s and 1990s showed renewed increases of illicit drug use in different regions of North America, and a corresponding increase in Europe and Latin American, albeit, at much lower levels compared with the United States (Hughes et al., 1983; Adlaf et al., 1997; Senay, 1991; MacCoun and Reuter, 1997; Smart, 1989; Wittchen et al., 1998a,b,c). This period of time in the United States coincided with the infamous 'crack' cocaine epidemic in the United States, the advent of designer drugs such as 'ecstasy,' increasing methamphetamine and marijuana use, and most recently a resurgence of heroin use. This is also the time period when children of peak consumption 'Baby Boomers' entered their teenage years, and these youth may have disproportionately experienced an intergenerational transmission of attitudes favorable to drug use. Nevertheless, overall rates of drug use in the United States have not returned to peak lifetime rates reported in the 1970s. In developed Western nations, as well as Australia and New Zealand, the few key studies that have been reported suggest drug use is reaching unprecedented levels of consumption despite remaining far below North American levels (Sylbing and Persoon, 1985; Muza et al., 1997; Carlini-Cotrim and Carlini, 1988). In less developed countries with traditional cultures, such as Nigeria, Egypt, Morocco, and India, rates remain far lower (Jutkowitz and Eu, 1994; Obot, 1990; World Health Organization, 1997).

Age of first drug use is an important risk factor for later dependence and experimentation with other drugs (Choquet et al., 1989; Escobedo et al., 1993; Hawkins et al., 1997; Kandel et al., 1992). However, early initiation of alcohol use as a predictor of progression to dependence and illicit drug use is not firmly established in international studies. Grant and Dawson (1997) reported a US rate of $40 \%$ lifetime alcohol dependence for those who started drinking at 14 years of age or younger, compared with only $10 \%$ for those who started at the age of 20 or older. Recent research has shown that younger age cohorts in the United States have used more drugs in their lifetime (SAMHSA, 1996). Early drug use is linked to negative consequences for social role functioning and impaired ability to make normative transitions from adolescence into adulthood (Newcomb and Bentler, 1988). The likelihood of higher educational attainment, forming successful marital unions, prospering in occupational pursuits, and avoiding mental disorders, is reduced by early initiation into drug use (Jutkowitz and Eu, 1994; Hawkins et al., 1992; Robins and Pryzbeck, 1985; Yu and Williford, 1992). It is an important public health goal to identify age of onset among nations and to determine the 
long-range consequences of these patterns. These are potentially harbingers of lost economic productivity, a host of secondary behavioral adjustment problems, and cost impact on the health care delivery system.

Historical evidence suggests that it is problematic to forecast drug epidemics and changing popularity cycles of different drugs. There are mediating factors, such as variations in normative behavioral expectations that undermine simplistic forecasting of future trends. The rise and decline in the crack epidemic in the United States, and its selective regional and ethnic-racial penetration into the population, was completely unforeseen and continues to lack a credible, empirically founded explanation. Identification of national risk factors, rather than individual or group risk factors, responsible for fluctuations in drug use patterns is premature at our current state of knowledge. Similarly, the preference or avoidance of nations or their constituent ethnic and demographic groups for specific drugs, such as heroin or methamphetamine, requires much greater scrutiny to arrive at a satisfactory explanation.

The study findings indicate that cultural assimilation into societies with high rates of drug use such as the United States or Canada may tend to accelerate the lifetime rates of drug use for newer immigrant groups from less developed nations toward the normative rates of these nations. Fresno, California, and its large Mexican origin population, provides an illustration of the consequences of moving from a low drug use to a high drug use society, and the extraordinarily degenerative impact on norms proscribing illicit drug use attributable to assimilation (Vega et al., 1998a). Detailed analyses of the Fresno data presented elsewhere have shown that nativity, acculturation level, gender, and location of residence independently contribute to lifetime illicit drug use in this population (Vega et al., 1998b). The influence of cultural and social assimilation appears to be progressive, and occurs within and across age cohorts with maximum effects on immigrants arriving as children (Turner and Gil, 2002). 'Long stay' adult immigrants have higher lifetime rates of all types of drug use compared with 'short stay' immigrants, and the second generation has even higher rates of drug dependence than 'long stay' immigrants (Vega et al., 1998a). Care must be taken to avoid premature closure in inferring causation. It is possible that reporting artifacts are having an unknown degree of influence on these self-reported rates. There may be a degree of underreporting in nations such as Mexico where fear of social stigma or punitive action resulting from personal disclosures of illicit drug use is prevalent. However, as discussed below in the limitations section, the magnitude of possible underreporting is unlikely to be great enough to distort the general patterns among sites reported in this study.

This example highlights an understudied area for international research, the regulation of drug use by social sanctions and cultural norms, and their modification subsequent to assimilation in another society. Rates are lower in Mexico City even though there is extensive illicit drug production and trafficking in Mexico. Future national surveys in Mexico will afford an opportunity to observe whether the current marginal levels of drug use accelerate as a consequence of continuing trafficking activity and return migration from the US, and which regions are most affected by these influences. These findings will have implications for other nations experiencing large increases in illicit drug use supply and immigration, such as the Caribbean Basin and the Andes region of South America.

Age-of-onset information reported in this study suggests a normative temporal ordering of peak onset from alcohol to cannabis to other drugs as a dominant pattern across study sites. This interpretation does not imply a progression sequence at the individual level since we have presented cross sectional data (Kandel et al., 1992). Perhaps somewhat counterintuitively, we detected no relationship between age of onset and prevalence levels for various 
substances in these regional and national samples. Age-of-onset patterns were fundamentally similar across sites regardless of wide variations in prevalence estimates and differences in legal age of drinking, suggesting a strong link to stages of adolescent development and the influence of social role transitions in early adulthood.

\subsection{Methodological limitations of the research}

Optimal and feasible strategies for pooling international data sets in the epidemiology of drug use are an important area of technical development. Even data sets sharing common data elements and design characteristics often have incompatibilities as well. The ICPE has selected various methodological techniques for different studies, including this one, and in some instances statistical artifacts may be produced by their use. It is important to acknowledge these possibilities in the context of improving the planning, execution, analyses, and interpretation of future multi-site international studies.

Variations in response rates could reflect an unknown degree of selection bias, and other methodological differences, such as synthetic cohort assumptions required for survival analysis, cannot be entirely dismissed as a potential source of error in the hazard rate estimations for age of onset reported in Figs. 1-3. Since the surveys are cross-sectional, the age-specific rates involve comparisons among persons from different birth cohorts (i.e. a synthetic cohort). Longitudinal studies or much larger cross-sectional samples would be necessary in order to produce reliable age-specific estimates by birth cohort. It is possible that different birth cohorts could exhibit different age peaks in the hazard rates; were this the case, it would have the effect of broadening the peaks in the synthetic cohort. However, the peaks observed in Figs. 1-3 are remarkably sharp, with the exception of the Mexico City rates for cannabis and other drugs, which do not show clear peaks. Given the low prevalence of drug use in Mexico City, the hazard rates are predictably small; and, hence, have less precision than the estimates from other sites with much higher levels of drug use. The mixture of birth cohorts could also affect the level estimated for the hazard rates. For example, some birth cohorts (such as older ones) might be more resistant to drug use, and their exclusion from the analysis would likely raise the levels of the estimated hazard rates. Hence, the estimated hazard rates are of more interest for their relative changes and peaks than their numerical values. Again, however, the cross-sectional nature of the surveys and their limited sample sizes do not permit precise estimation of rates by birth cohort.

It should be noted that the lifetime prevalence rates shown in Tables 2 and 3 reflect the nature and structure of the different study populations, including their differing age distributions. The site age distributions differ due to two factors: first, there are population differences, and, second, the samples had restricted age ranges that were not uniform. The Munich, Germany survey included only 14-25 year olds, thus limiting the comparability of this site to the other studies. All samples were constrained to respondents between 14 and 54 years, however, most of the samples did not have respondents under 18 years of age with the upper cut off being 54 . There are alternative ways to present the prevalence data in Tables 1 and 2 that were not pursued here due to space limitations. One would be to standardize the age and gender distributions to some reference population. Although useful for comparison purposes, standardized rates are hypothetical constructs, and the non-standardized rates shown in Tables 1 and 2 reflect the actual level of substance use in the site populations. We invite interested readers to review an additional analyses on the journal web site that suggest age distributions of the samples are not affecting the prevalence rates presented in Tables 2 and 3. 
The use of a diagnostic case-finding protocol, the CIDI, as the core instrument common to all survey sites, made it feasible to conform the standard of lifetime drug use in this study to respondent use on at least five occasions, and to at least 12 occasions for alcohol, in any 1 year. We consider these operational criteria to represent a reasonable behavioral standard for estimating lifetime rates of drug use. Alternative standards, such as first use in a lifetime, or substance abuse or dependence diagnostic criteria, are other commonly used standards for estimating lifetime rates. Our intent was to identify prevalence and onset of persistence substance use, thus signaling self reinforcing behavior. Using these alternative standards could produce different results than reported here, especially if use in some nations or genders occurs disproportionately at frequencies below the threshold used in this study. However, the hazard curves presented in Figs. 1-3 are estimated based on the self-report of first use in a lifetime. Only four sites (US, Fresno, USA, Ontario, Canada, and Mexico) were included in these figures because the others did not collect information on first use in a lifetime. This underscores the importance of careful planning in advance of data collection to assure uniformity of data elements, not just core protocols such as the CIDI that are based on diagnostic criteria structure.

There are also other issues not addressed in this study that may provide important additional information. Heterogeneous populations pose a variety of challenges for inclusion of subgroups least likely to be included in household samples, such as institutionalized populations, drug addicts, migrants, and the homeless.

It is our opinion that artifacts, such as weighting prevalence estimates by site, veracity of self report data, and recall fallibility, do not fundamentally alter the patterns in reported rates. There is indirect evidence of reliability and validity from other studies. We have previously presented a comparison of DSM-III-R substance abuse or dependence rates in Fresno, California, using local county and US national (NCS) post stratification weighting for age and sex and found relatively minor differences (Vega et al., 1998). All major population surveys conducted in Mexico over many years have reported similarly low rates of illicit drug use, with negligible use among women, and previous research showed no differences in self-report veracity between Spain, Mexico, and the United States. A very large representative sample $(\mathrm{N} / 28$ 000) of pregnant women in California was surveyed using anonymous urine toxicology screening in hospitals and negligible illicit drug use was found among Mexican immigrants (Vega et al., 1997). Rates for Mexican /American women were higher, with proportional differences similar in magnitude to those observed in the Fresno survey (Vega et al., 1998).

\subsection{Future directions}

International comparative studies have the unique value of permitting direct contrasts of levels of use by drug type and patterns of onset. Comparative studies also illustrate both methodological possibilities and challenges. These data taken from seven ICPE sites report wide variations across nations that provoke important research and policy questions. Can we anticipate a gender convergence in onset rates in developed nations and a corresponding convergence in abuse or dependence rates as younger age cohorts mature (Neve et al., 1996)? Will length of time between first use of individual drugs and onset of dependence vary in national samples? What is the relative vulnerability of urban and rural areas to drug use in different nations? How consistently across nations are immigrants and their offspring vulnerable to increased consumption patterns of drugs use after resettlement in high consumption nations? The future inclusion of comparable data from the WHO World Mental Health 2000 surveys in two dozen nations will provide an unprecedented opportunity to 
address many aspects of international substance use epidemiology and its economic impact on these societies, and will afford a unique possibility of planning and evaluating prevention and treatment programs in an international context (Fillmore et al., 1993).

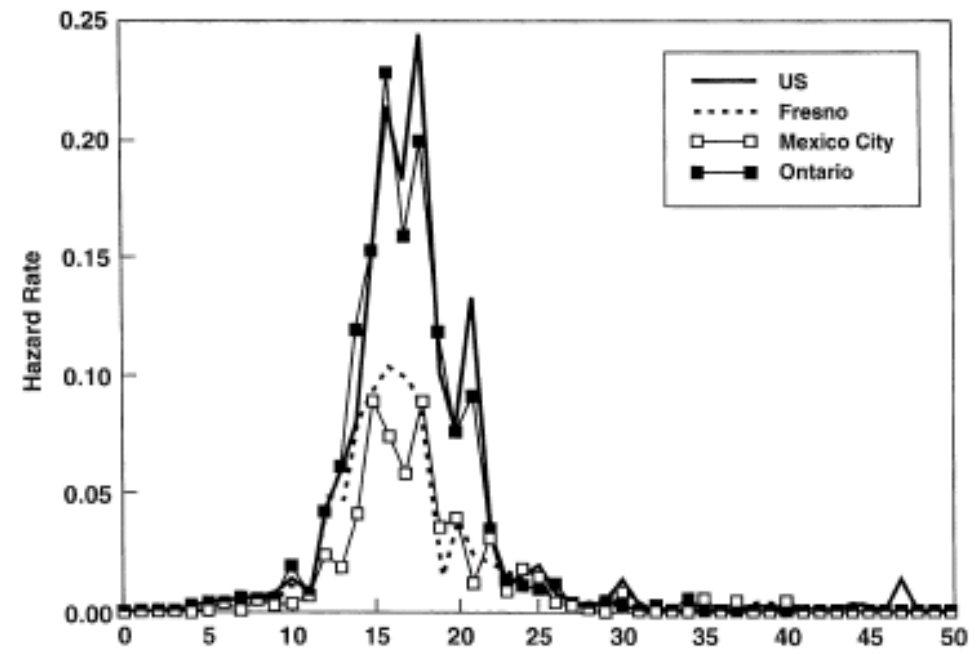

Fig. 1. Years to first use of alcoholestimated from four surveys conducted in Ontario, Canada, Mexico City, Fresno, Cahifornia and using a national sample from the United Statex. Data are expressad as the rates that persons of a specific age will experience first use of alcohol.

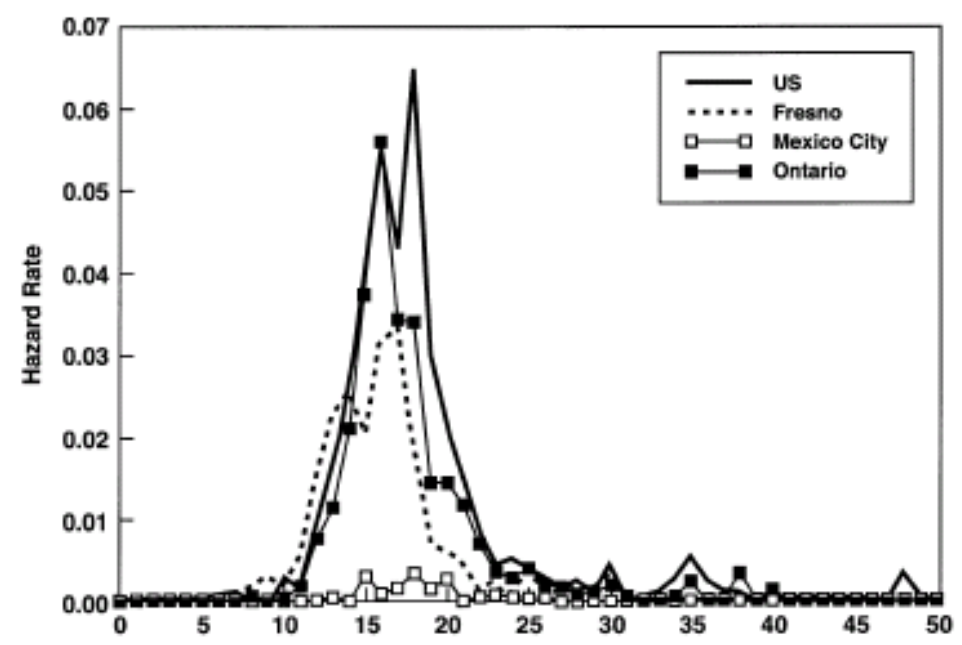

Fig. 2. Years to first use of cannabis estimated from four surveys conduded in Ontario, Canada, Mexico City, Fresno, California and using a national sample from the United States. Data are expressed as the rates that persons of a specific age will experience first use of cannabis. 


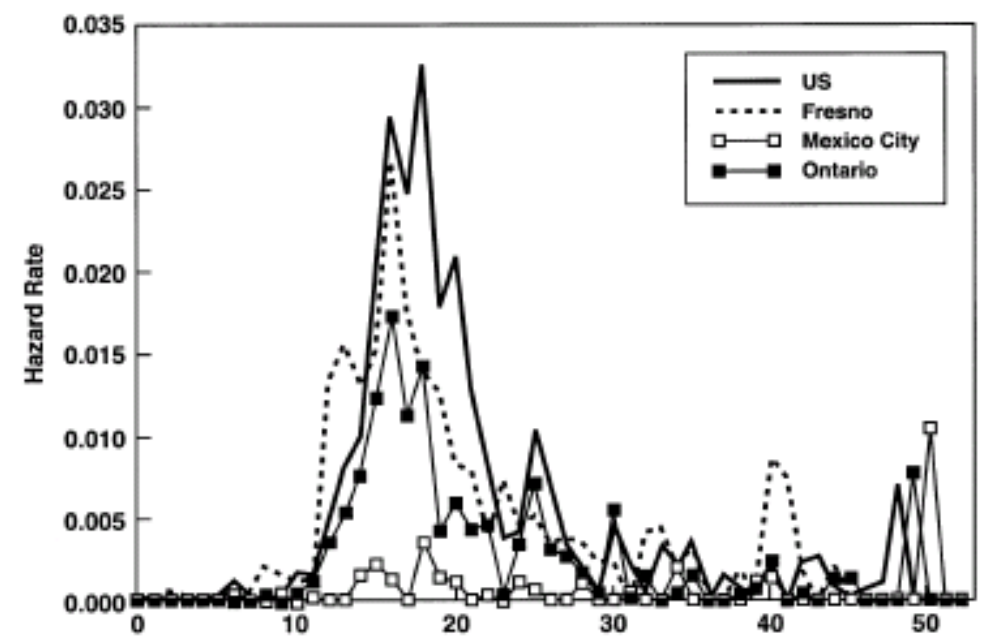

Fig. 3. Years to first use of other drugs estimated from four surveys conducted in Ontario, Canada, Mexico City, Fresno, California and using a national sample from the United States. Data are expresed as the rates that persons of a specific age will experience first use of 'other drugs, 'which include stimulants, cocaine, anxiolytics, opioids, psychedelics or inhalants.

Table 1

Seven population surveys used for comparisons of prevalence and age of onset of substance use

\begin{tabular}{lllrrrl}
\hline Site & Study & $n$ & Ages & Year & Response (\%) & Citation \\
\hline USA & NCS & 5872 & $15-54$ & $1990-1992$ & 84.4 & Kessler et al., 1994 \\
Fresno, CA & MAPSS & 2874 & $18-99$ & $1995-1997$ & 90.0 & Vega et al., 1998 \\
Mexico Gity, Mexico & EPM & 1734 & $18-65$ & 1995 & 60.4 & Caraveo-Anduaga et al., 1998 \\
Ontario, Canada & MHS-OHS & 6902 & $15+$ & $1990-1991$ & 88.1 & Offord et al., 1994 \\
Netherlands & NEMESIS & 5825 & $18-64$ & 1996 & 70.0 & Bijl et al., 1998 \\
Sä Paulo, Brazil & ECAS & 1027 & $18-64$ & $1994-1996$ & 65.2 & Andrade, 1996 \\
Munich, Germany & EDSP & 3021 & $14-25$ & 1995 & 71.1 & Wittchen et al., 1998a,b \\
\hline
\end{tabular}

All respondents in these studies were within the age range of $14-54$. 


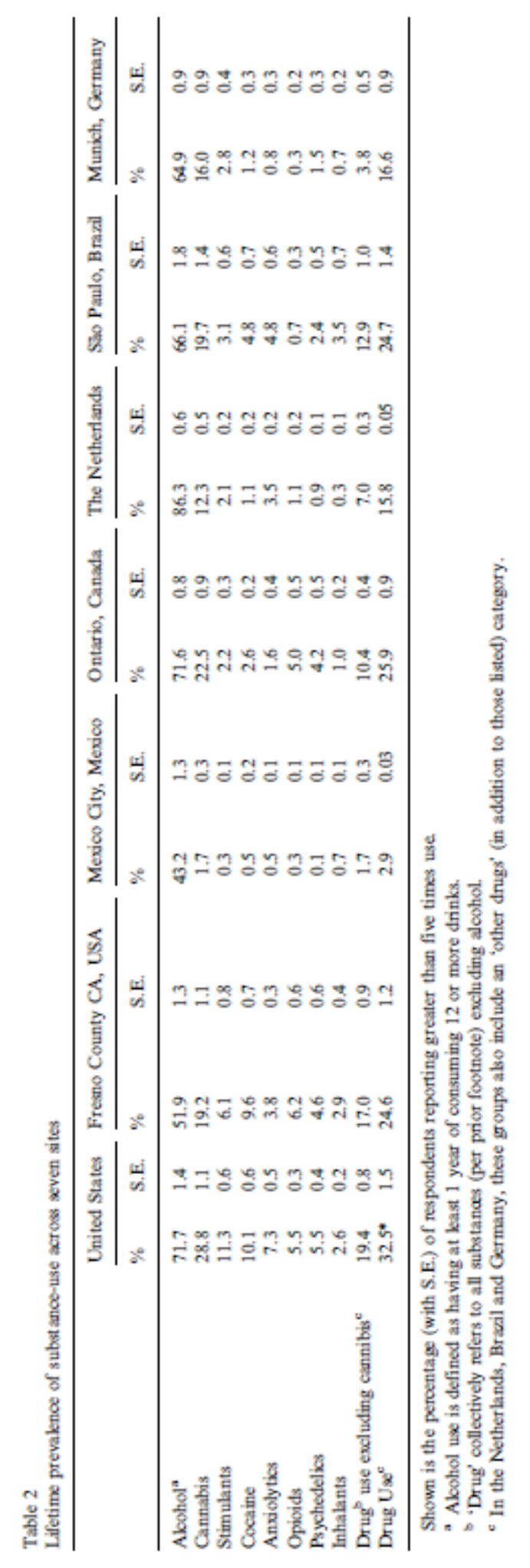




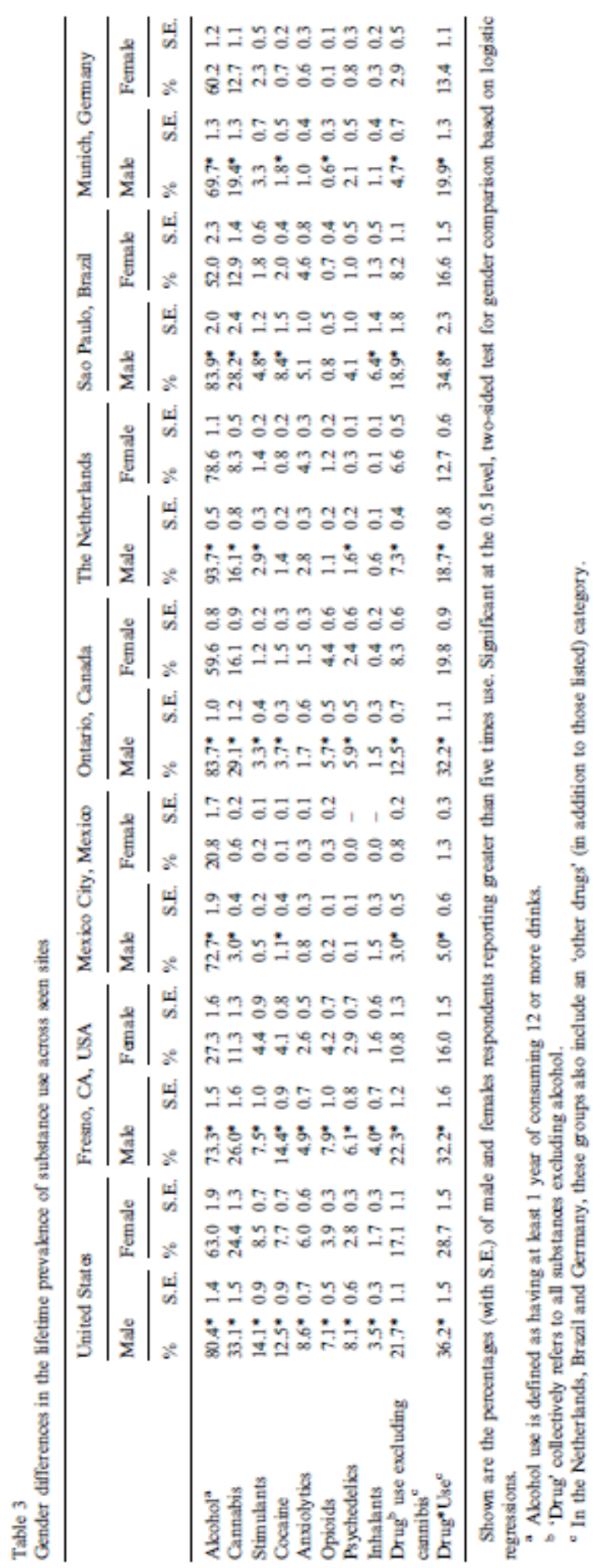

\section{Acknowledgements}

The International Consortium in Psychiatric Epidemiology (ICPE) is supported by a grant from the National Institute of Health (NIH) DA 11121. Data from seven surveys are presented in this report. The MAPSS research was supported by grant DA 12167 and NIH grant TW 00061. The EDSP is funded by the German Ministry of Research and Education (BMBF) as part of the Addiction Research Initiative (01EB94056). The EPM was funded by grant 2077- H9302 of the National Council of Science and Technology (CONACYT). NEMESIS is funded by the Netherlands Institute of Mental 
Health and Addiction (Trimbosinstituut) in Utrecht. Financial support has been received from the Netherlands Ministry of Health, Welfare and Sport (VWS), the Medical Sciences Department of the Netherlands Organization of Scientific Research (NOW), and the National Institute of Public Health and Environment (RIVM). The Ontario Mental Health Supplement was supported by funds from the Premier's Council-Ministry of Community and Social Services, the Ministry of Health, and the Ontario Mental Health Foundation. The ECA-Ipq-SP study was funded by FAPESP, a funding agency from the State of Sao Paulo (Projecto Tema'tico n.o 93/0501-4). Finally, The NCS was supported by grants from the National Institute of Mental Health MH46376 and MH 49098, W.T. Grant Foundation 90135190, and a Research Scientist Development Award MH 00507.

\section{References}

- Abelson, H.I., Miller, J.D., 1985. A decade of trends in cocaine use in the household population, cocaine use in America, epidemiologic and clinical perspectives. NIDA Research Monograph 61, 35-49.

- Adlaf, E.M., Ivis, F.J., Smart, R.G., 1997. Ontario Student Drug Survey. Addiction Research Foundation, Toronto.

- Andrade, L., 1996. Lifetime prevalence of mental disorders in a catchment area in Sao Paulo, Brazil. Paper presented at the VII Congress of the International Federation of Psychiatric Epidemiology, Santiago, Chile, August 1996.

- Adrian, M., 1996. Substance use and multiculturalism. Substance Use and Misuse 31, 14591501.

- Anthony, J.C., Helzer, J.E., 1991. Syndromes of drug abuse and dependence. In: L.N. Robins, D.A. Regier, Psychiatric Disorders in America: The Epidemiologic Catchment Area Study, Free Press: N.Y., pp. 116-154.

- Bijl, R.V., Van Zessen, G., Ravelli, A., de Rijk, C., Langendoen, Y., 1998. The Netherlands mental health survey and incidence study (NEMESIS): objectives and design. Social Psychiatry Psychiatric Epidemiology 33, 581-586.

- Black, S., Casswell, S., 1993. Drugs in New Zealand: A Survey, 1990, Alcohol and Public Health Research Unit. University of Auckland.

- Burke, K.C., Burke, J.D., Jr, Rae, D.S., Regier, D.A., 1991. Compare age at onset of major depression and other psychiatric disorders by birth cohorts in five US community populations. Archives of General Psychiatry 48, 789-795.

- Caetano, R., Carlini-Cotrim, E.A., 1993. Perspectives on alcohol epidemiology research in South America. Alcohol Health and Research World 17, 244-250.

- Caravalho, V., Pinsky, I., De Souza, E., Silva, R., Carlini-Cotrim, B., 1995. Drug and alcohol use and family characteristics: a study among Brazilian high-school students. Addiction 90, 65-72.

- Caraveo-Anduaga, J., Martinez, J., Rivera, B., 1998. A model for epidemiological studies on mental health and psychiatric morbidity. Salud Mental 21 (1), 48-57.

- Caraveo-Anduaga, J., Colmenares-Bermudez, E., Saldivar-Hernandez, G.J., 1999. Gender differences in alcohol consumption in Mexico City. Salud Publica-Mexico 41 (3), 177-188.

- Carlini-Cotrim, B., Carlini, E.A., 1988. The use of solvents and other drugs among children and adolescents from a low socioeconomic background: a study in Sao Paulo, Brazil. International Journal of the Addictions 23, 1145-1156.

- Choquet, M., Menke, H., Ledoux, S., 1989. Self-reported alcohol consumption among adolescents and the signification of early onset. Social Psychiatry and Psychiatric Epidemiology 24, 102-112.

- DeZwart, W.M., Stam, H., Kuipers, S.B.M., 1997. Kerngegevens: Roken, Drinken, Drugsbgebruik on Gokken Onder Scholieren vanaf 10 Jaar. Trimbos-Instituut, Utrecht, Netherlands.

- Driessen, F.M., VanDam, G., Olsson, B., 1989. Tijdschr. Alcohol Drugs Andere Psychotrope Stotten $15,2$. 
- $\quad$ Erickson, P.G., Adlaf, E.M., Murray, G.F., Smart, R.G., 1987. The Steel Drug: Cocaine in Perspective. Lexington Books, Toronto, pp. 83-87.

- Escobedo, L.G., Marcus, S.E., Holtzman, D., Giovino, G.A., 1993. Sports participation, age at smoking initiation, and the risk of smoking among US high school students. Journal of the American Medical Association 269, 1391-1395.

- Fillmore, K.M., Golding, J.M., Leino, E.V., Motoyoshi, M., Shoemaker, C., Terry, H., Ager, C.R., Ferrer, H.P., 1993. Crossnational comparisons of drinking behavior as determined from the collaborative alcohol-related longitudinal project. Alcohol Health and Research World 17, 198-204.

- Galvan-Reyes, J., Ortiz-Castro, A., Gonzalez-Uribe, L., 1997. El sistema de registro de informacion sobre drogas: un auxliar diagnostico en la evaluacion de la farmacodependencia. Salud Publica Mexico 39, 61-68.

- Grant, B.F., 1996. Prevalence and correlates of drug use and DSM-IV drug dependence in the United States: results of the national longitudinal alcohol epidemiologic survey. Journal of Substance Abuse 8, 195-210.

- Grant, B.F., 1997. Prevalence and correlates of alcohol use and DSM-IV alcohol dependence in the United States. Results of the national longitudinal alcohol epidemiologic survey. Journal of Studies on Alcohol 58, 464-473.

- Grant, B.F., Dawson, D.A., 1997. Age of onset of alcohol use and its association with DSMIII-IV alcohol abuse and dependence: results from the national longitudinal alcohol epidemiologic survey. Journal of Substance Abuse 9, 103-110.

- Hawkins, J.D., Catalano, R.F., Miller, J.Y., 1992. Risk and protective factors for alcohol and other drug problems in adolescence and early adulthood: implications for substance use prevention. Psychological Bulletin 112, 64-105.

- Hawkins, J.D., Graham, J.W., Maguin, E., Abbot, R., Hill, K.G., Catalano, R.F., 1997. Exploring the effects of age of alcohol use initiation and psychosocial risk factors on subsequent alcohol misuse. Journal of Studies on Alcohol 58, 280-290.

- Heeringa, S.G., Liu, J., 1998. Complex sample design effects and inference for metal health survey data. International Journal of Methods in Psychiatric Research 7, 56-65.

- Heeringa, S.G., Little, R.J., Lepkowshi, J., Kessler, R.C., 1997. Assessment weighting methodology for the National Comorbidity Study. Amer. J. Epidem. 46 (5) 439-449.

- Hegan, C., Carley, K., Strickler, G., 2001. Societal cost of substance abuse, the economic cost of substance abuse to the US economy. Substance Abuse: The Nation's Number One Health Problem, the Context of Substance Abuse, Published report prepared by the Schneider Institute for Health Policy, Brandeis University, for the Robert Wood Johnson Foundation, February 2001.

- Holly, A., Wittchen, H.U., 1998. Patterns of use and their relationship to DSM-IV abuse and dependence of alcohol among adolescents and young adults. European Addiction Research 4, 50-57.

- Hughes, P.H., Canavan, K.P., Jarvis, G., Arif, A., 1983. Extent of drug abuse: an international review with implications for health planners. World Health Statistics Quarterly 36, 394-497.

- Johnston, L.D., O’Malley, P.M., Bachman, J.G., 1997. National survey results on drug use from the monitoring the future study, 1975-1995, Rockville, MD, National Institute on Drug Abuse. Journal of Social Medicine 1, 31-39.

- Jutkowitz, J.M., Eu, H., 1994. Drug prevalence in Latin American and Caribbean countries: a cross-national analysis. Drugs: Education, Prevention and Policy 1, 199-252.

- Kalbfleisch, J.D., Prentice, R.L., 1980. The Statistical Analysis of Failure Time Data. Wiley, New York.

- Kandel, D.B., Yamaguchi, K., Chen, K., 1992. Stages of progression in drug involvement from adolescence to adulthood: further evidence for the gateway theory. Journal of Studies on Alcohol 53, 447-457.

- Kessler, R.C., 1995. The national comorbidity survey: preliminary results and future directions. International Journal of Methods in Psychiatric Research 5, 139-151. 
- Kessler, R.C., McGonagle, K.A., Zhao, S., Nelson, C.B., Hughes, M., Eshlemans, S., Wittchen, H.U., Kendler, K., 1994. Lifetime and 12-month prevalence of DSM-III-R psychiatric disorders in the United States. Gen Psychiatry 51, 8-19.

- Kessler, R.C., Aguilar-Gaxiola, S., Andrade, L., Bijl, R., Borges, G., Caraveo-Anduaga, J.J., DeWit, D., Kolody, B., Merikangas, K.R., Molnar, B.E., Vega, W.A., Walters, E.E., Wittchen, H.U., 1999. Cross-national comparisons of commorbidities between substance use disorders: results from the international consortium in psychiatric epidemiology. In: Handbook for Drug Abuse Prevention Theory, Science, and Practice.

- Kish, L., 1965. Survey Sampling. Wiley, New York, pp. 83-95.

- Korf, D.J., 1988. Tijdschr. Alcohol Drugs Andre Psychotrope Stotten 14, 81.

- Little, R.J.A., 1991. Inference with survey weights. Journal of Official Statistics 7, 405-424.

- MacCoun, R., Reuter, P., 1997. Interpreting Dutch cannabis policy: reasoning by analogy in the legalization debate. Science 278, 47-51.

- Medina-Mora, M.E., Rojas, E., Juarez, F., Berenzon, S., Carreo, S., Galvan, J., Villatoro, J., Lopez, E.K., Olmedo, R., Ortiz, E., Equiz, G., 1993. Consumo de sustancias con efectos psicotropicos en la poblacion estudiantil de enseananza media y media superior de la Republica Mexicana. Salud Mental 16, 2-8.

- Merikangas, K.R., Mehta, R.L., Molnar, B.E., Walters, E.E., Swendsen, J.D., AguilarGaxiola, S., Bijl, R., Borges, G., Caraveo-Anduaga, J.J., Dewit, D.J., Kolody, B., Vega, W.A., Wittchen, H.U., Kessler, R., 1998. Comorbidity of substance use disorders with mood and anxiety disorders: results of the international consortium in psychiatric epidemiology. Addictive Behavior 23, 893-907.

- Muza, G.M., Bettio, H., Muccillo, G., Barbieri, M.A., 1997. The consumption of psychoactive substances by adolescents in schools in Ribeirao Preto, SP.I. Prevalence of consumption of alcoholic beverages and liver cirrhosis mortality in Mexico. Revista de Saude Pública 39, 21 29.

- National Drug Strategy, 1996. Household Survey: Survey Report 1995. Commonwealth Dept. of Health and Family Services. Australian Government Publishing Office, Canberra.

- National Institute on Drug Abuse, 1998. Drug abuse costs to society at 97.7 billion dollars. NIDA Notes 13:1.

- Neve, R.J.M., Drop, M.J., Lemmens, P.H., Swinkels, H., 1996. Gender differences in drinking behavior in the Netherlands: convergence or stability. Addiction 91, 357-373.

- Newcomb, M.D., Bentler, P.M., 1988. Consequences of Adolescent Drug Use. Sage, Newbury Park, CA, pp. 173-177.

- Obot, I.S., 1990. Substance abuse, health and social welfare in Africa: an analysis of the Nigerian experience. Social Science and Medicine 31, 699-704.

- Offord, D.R., Cambell, D., Cochrne, J., Goering, P.N., Lin, E., Rhodes, A., Wong, M., 1994. Mental Health in Ontario: Selected Findings from the Mental Health Supplement to the Ontario Health Survey. Queen's Printer of Ontario, Toronto.

- Perkonigg, A., Lieb, R., Wittchen, H.U., 1998. Substance use, abuse, and dependence in Germany: a review of selected epidemiologic data. European Addiction Research 4, 8 -17.

- Robins, L.N., Pryzbeck, T.R., 1985. Age of Onset of Drug Use as a Factor in Drug and Other Disorders, NIDA Research Monograph No. 56. National Institute of Drug Abuse, Rockville, MD, pp. 178-192.

- SAMHSA, 1996. Trends in the incidence of drug use in the United States, 1919-1992, US Department of Health and Human Services, Rockville, MD.

- Sandwijk, J.P., Cohen, P.D.A., Musterd, S., 1991. Licit and Illicit Drug Use in Amsterdam II. Instituut voor Sociale Geografie, Universiteit van Amsterdam, Amsterdam, pp. 87-91.

- Scholz, M., Kaltenbach, M., 1995. Cigarrette, alcohol and drug use in 12-13-year old adolescents-an anonymous survey of 2979 students. Gesundheitswesen 57, 339-344.

- Senay, E.C., 1991. Drug abuse and public health: a global perspective. Drug Safety 6, 1 -65.

- Smart, R.G., 1989. Is the postwar drinking binge ending? Crossnational trends in per capita alcohol consumption. British Journal of Addiction 84, 743-748.

- Smart, R.G., Murray, G.F., 1985. Narcotic drug abuse in 152 countries: social and economic conditions as predictors. International Journal of the Addictions 20, 737-749. 
- $\quad$ Smart, R.G., Murray, G.F., Arif, A., 1988. Drug abuse and prevention programs in 29 countries. International Journal of the Addictions 23, 1-17.

- Soyka, M., 1998. Social psychiatry aspects of alcoholism: epidemiology, treatment structures and recent result of therapy research. Gesundheitswesen 60, 87-94.

- Sylbing, G., Persoon, J.M.G., 1985. Cannabis use among youth in the Netherlands. Bulletin on Narcotics 37, 51-60.

- Tapia-Conyer, R., Cravioto, P., Borges-Yanez, S.A., De la Rosa, B., 1996. Consumption of prescription drugs in 60-65-years old population in Mexico, National survey on addictions, 1993. Salud Publica de Mexico 38, 458-465.

- Turner, R.J., Gil, A.G., 2002. Psychiatric and substance abuse disorders in South Florida: Racial/ethnic and gender contrasts in a young cohort. Arch. Gen. Psychiatry 59, 43-50.

- Uchtenhagen, A., 1984. Global assessment and epidemiology of cocaine in Europe. Paper presented at the WHO Advisory Group Meeting on Adverse Health Consequences of Cocaine and Coca Paste Smoking, Bogota, 10-14 September 1984.

- United Nations International Drug Control Programme (UNDCP), 1997. World drug report, Oxford University Press, New York.

- US Department of Health and Human Services, 1997. Epidemiology of Alcohol Use and Alcohol-related Consequences. In: Ninth Special Report to the US Congress on Alcohol and Health, Washington, DC, pp. 1-31.

- Vega, W.A., Kolody, B., Noble, Porter, 1997. Perinatal drug use among immigrant and native born Latinas. Substance Use and Misuse 32, 43-60.

- Vega, W.A., Gil, A.G., 1998. Acculturative stress and drug use behavior among immigrant and US born Latino adolescents: toward an integrated model. Reprinted in: De la Rosa, M.R., Segal, B., Lopez, R. (Eds.), Conducting Drug Abuse Research with Minority Populations.

- Vega, W.A., Alderete, E., Kolody, B., Aguilar-Gaxiola, S., 1998a. Illicit drug use among Mexicans and Mexican Americans in California: the effects of gender and acculturation. Addiction 93, 1839-1850.

- Vega, W.A., Kolody, B., Aguilar-Gaxiola, S., Alderete, E., Catalano, R., Caraveo-Anduaga, J., 1998. Lifetime prevalence of DSM-III-R psychiatric disorders among Urban and Rural Mexican Americans in California. Archives of General Psychiatry 55, 771-778.

- Williams, B., Chang, K., Truong, M.V., Saad, F., 1994. International Profile of Alcohol and Other Drugs. Addiction Research Foundation.

- Wittchen, H.U., Muller, N., Storz, S., 1998. Psychische Störungen: -Häufigkeit, psychosoziale Beeinträchtigungen und Zusammenhange mit körperlichen Erkrankungen. Das Gesundheitswesen 2, 95-100.

- Wittchen, H.-U., Nelson, C.B., Lachner, G., 1998. Prevalence of mental disorders and psychosocial impairments in adolescents and young adults. Psychological Medicine 28, 109126.

- Wittchen, H.U., Perkonigg, A., Lachner, G., Nelson, C.B., 1998. Early developmental stages of psychopathology study (EDSP)-objectives and design. European Addiction Review 4, 18 27.

- World Health Organization (WHO), 1997. Guide to Drug Abuse Epidemiology: PrePublication version. Division of Mental Health and Prevention of Substance Abuse, Geneva.

- Wolter, K.M., 1965. Introduction to Variance Estimation. Springer, New York, pp. 153-200.

- Xie, X., Rehm, J., Single, E., Robson, L., Paul, J., 1998. The economic costs of alcohol abuse in Ontario. Pharmacological Research 37, 241-249.

- Yu, J., Williford, W.R., 1992. The age of alcohol onset and alcohol, cigarette and marijuana use patterns: an analysis of drug use progression of young adults in New York State. International Journal of the Addictions 27, 1313-1323. 